\title{
JM
}

Volume 6 No. 2 (Oktober 2018)

(C) The Author(s)

\section{DESKRIPSI KARAKTERISTIK PADA REMAJA TERHADAP HIV / AIDS DI SMAN 3 SELUMA TAHUN 2017}

\section{DESCRIPTION OF CHARACTERISTICS IN ADOLESCENT TO HIV / AIDS IN SMAN 3 SELUMA IN 2017}

\author{
WINDA LIDIA FITRIA, FIYA DINIARTI, VENTI KUSUMA
}

\begin{abstract}
ABSTRAK
Kasus HIV / AIDS di Dunia, hampir 7 juta orang yang menderita penyakit mematikan ini dan di Indonesia pada tahun 2016 melaporkan sebanyak 276.428 kasus. Sedangkan untuk remaja dengan batas usia 15-19 tahun di Indonesia ada 2.208 kasus HIV / AIDS. Penelitian ini bertujuan untuk mengetahui karakteristik remaja terhadap HIV / AIDS di SMA 3 Seluma tahun 2017. Penelitian ini merupakan penelitian deskriptif, populasi dalam penelitian ini adalah seluruh siswa di SMA 3 Seluma Kelas X tahun 2017 yang berjumlah 175 orang, dengan sampel 69 orang. Teknik simple proportionate stratified random sampling yang digunakan untuk mengambil sampel untuk mewakili dari kelas X yang terdiri dari 5 kelas. Hasil penelitian ini menunjukkan bahwa karakteristik remaja terhadap HIV / AIDS di SMA 3 Seluma tahun 2017, sebagian besar responden $(68,1 \%)$ adalah perempuan, sebagian besar responden $(76,8 \%)$ berpengetahuan dan sebagian besar responden ( 53,6\%) kurang mengetahui tentang HIV / AIDS di SMAN 3 SELUMA 2017. Hal ini diharapkan dapat meningkatkan perilaku atau sikap remaja terhadap pencegahan HIV / AIDS dan sebagai bahan informasi dan umpan balik untuk pelaksanaan program penanggulangan HIV / AIDS terutama di kalangan remaja.
\end{abstract}

Kata kunci : Karakteristik, HIV / AIDS

\begin{abstract}
Cases of HIV / AIDS in the World, nearly 7 million people who suffer from this deadly disease and in Indonesia in 2016 reported as many as 276,428 cases. Meanwhile, for adolescents with age limit of 15-19 years in Indonesia there are 2,208 cases of HIV / AIDS. This study aims to find out the characteristics of youth to HIV / AIDS in SMA 3 Seluma in 2017. This research is a descriptive research, the population in this research were all students in SMA 3 Seluma Class X in 2017 of 175 people, with the sample of 69 people. Simple proportionate stratified random sampling techniquewas used to take the sample to represent from class X consisting of 5 classes using. The results of this study indicated that the characteristics of adolescents to HIV / AIDS in SMA 3 Seluma in 2017 that, most of the respondents (68.1\%) were female, most of the respondents $(76.8 \%)$ were knowledgeable and most of the respondents $(53.6 \%)$ were unfavorable towards HIV / AIDS in SMAN 3 SELUMA 2017. It is expected to improve the behavior or attitudes of adolescents to the prevention of HIV / AIDS and as an information and feedback material for the implementation of HIV / AIDS eradication program especially among adolescents.
\end{abstract}




\section{PENDAHULUAN}

Jumlah kasus HIV/AIDS dari tahun ketahun diseluruh bagian dunia terus meningkat meskipun berbagai upaya preventif terus dilaksanakan. Estimasi penduduk dunia yang menderita HIV pada tahun 2016 adalah 38 juta orang dengan angka kematian sekitar dua juta orang. Kasus HIV/AIDS di Indonesia pada tahun 2016 dilaporkan sebanyak 276.428 kasus. Sementara itu untuk usia remaja dengan batasan usia 15-19 tahun di Indonesia terdapat 2.208 kasus HIV/AIDS.Afrika Selatan menjadi negara dengan jumlah penderita HIV/AIDS terbesar di Dunia, nyaris 7 juta penduduk yang menderita penyakit mematikan ini. Jumlah ini nyaris mendekati $20 \%$ jumlah penduduk produktif di Afrika Selatan.Kemudian disusul Nigeria,dengan angka penderita HIV/IADS mencapai 3,2 juta jiwa dengan kematian setiap tahunnya mencapai lebih dari 200.000 jiwa. India menjadi satu-satunya negara di Asia yang memiliki jumlah penderita HIV/AIDS terbesar di dunia. Negara yang terletak di anak benuaAsia ini memiliki sekitar 2 juta penduduk yang mengidap HIV/AIDS. Dari jumlah itu, penduduk yang meninggal sekitar 130.000 setiap bulan. Rata-rata penderita dari penyakit ini hidup di lingkungan kumuh yang jarang tersentuh fasilitas kesehatan terbaik.kemudian disusul negara Zimbawe, Tanzania, Uganda, Kenya, Amerika, dan Rusia. Indonesia sendiri juga memiliki 660.000 penduduk dengan jumlah HIV/AIDS atau masih di bawah Tiongkok dan Brasil(Adi Nugroho, 2016).

Epidemi HIV di Asia masih banyak terkonsentrasi pada Injecting Drug Users (IDU), laki-laki yang berhubungan seks dengan sesamanya dan penjajan seks (heteroseksual maupun homoseksual) beserta pelanggan maupun pasangan seks tetapnya. Penularan yang penting termasuk penetrasi tanpa kondom antara laki-laki, pengguna narkoba suntik, suntikan yang tidak aman dan transfusi darah (WHO, 2015).

Pendataan yang dilakukan oleh World Health Organization (WHO) selama beberapa tahun terakhir menunjukkan bahwa kelompok remaja produktif merupakan salah satu kelompok yang paling rentan terhadap HIV/AIDS. Kasus HIV/AIDS di Indonesia pada tahun 2016 dilaporkan sebanyak 276.428 kasus. Sementara itu untuk usia remaja dengan batasan usia 15-19 tahun di Indonesia terdapat 2.208 kasus HIV/AIDS (Adi Nugroho, 2016).

Kasus di Indonesia penyakit yang menyerang sistem kekebalan tubuh ini,senantiasa meningkat dari tahun ke tahun, bahkan Indonesia merupakan Negara dengan penyebaran HIV dan AIDS tercepat di Asia (Yunanto, 2008).

Berdasarkan survei awal yang di lakukan di SMAN 3 Seluma Tanggal 16 juni tahun 2017 dari hasil yang diwawancarai terdapat 15 siswa dikelas $\mathrm{X}$ dari jumlah siswa kelas $\mathrm{X}$ berjumlah 175 orang, 8 siswa telah mengetahui tentang HIV/AIDS, penyebab terjadinya HIV/AIDS, gejala HIV/AIDS, cara menghindari HIV/AIDS dan 7 siswa belum mengetahui tentang apa itu HIV/AIDS, bagaimana menangani agar tidak tertular penyakit HIV/AIDS, belum mengetahui penyebab terjadinya HIV/AIDS. Berdasarkan latar belakang tersebut di atas, peneliti tertarik untuk meneliti gambaran jenis kelamin, pengetahuan, sikap remaja tentang HIV/AIDS di SMA (Sekolah Menengah Atas) 3 Seluma tahun 2017. Tujuan penelitian ini adalah diketahui gambaran karakteristik remaja terhadap HIV/AIDS di SMA 3 Seluma tahun 2017.

\section{METODE PENELTIAN}

Jenis penelitian ini merupakan penelitian deskriptif . Populasi adalah seluruh remaja SMA 3 Seluma Kelas X tahun 2017" berjumlah 175 orang. Sampel yang diambil dalam penelitian ini adalah 64 sampel 
dengan teknik probability sampling jenis Proposional Stratified random sampling. Pengumpulan data menggunakan data primer dan data sekunder.

\section{HASIL PENELITIAN}

Tabel. 1 Distribusi Frekuensi Jenis Kelamin Remaja terhadap HIV/AIDS di SMAN 3 Seluma Tahun 2017

\begin{tabular}{cccc}
\hline No & $\begin{array}{c}\text { Jenis } \\
\text { Kelamin }\end{array}$ & $\begin{array}{c}\text { Frekuensi } \\
\text { ( f })\end{array}$ & $\begin{array}{c}\text { Persentase } \\
(\mathbf{\%})\end{array}$ \\
\hline 1 & Perempuan & 46 & 71,9 \\
\hline 2 & Lak-Laki & 18 & 28,1 \\
\hline & Total & 64 & 100.0 \\
\hline
\end{tabular}

Berdasarkan tabel diatas diketahui dari 64 responden terdapat sebagian besar responden $(71,9 \%)$ berjenis kelamin perempuan di SMAN 3 Seluma Tahun 2017.

Tabel. 2 Distribusi Frekuensi Pengetahuan Remaja terhadap HIV/AIDS di SMAN 3 Seluma Tahun 2017

\begin{tabular}{cccc}
\hline No & Pengetahuan & $\begin{array}{c}\text { Frekuensi } \\
(\mathbf{f})\end{array}$ & $\begin{array}{c}\text { Persentase } \\
(\mathbf{\%})\end{array}$ \\
\hline 1 & Kurang & 2 & 3,1 \\
\hline 2 & Cukup & 13 & 20,3 \\
\hline 3 & Baik & 49 & 76.6 \\
\hline & Total & 64 & 100 \\
\hline
\end{tabular}

Berdasarkan tabel diatas dapat diketahui dari 64 responden terdapat sebagian besar responden $(76,6 \%)$ berpengetahuan baik tentang HIV/AIDS di SMAN 3 Seluma Tahun 2017.

Tabel 3. Distribusi Frekuensi Sikap Remaja tentang HIV/AIDS di SMAN 3 Seluma Tahun 2017

\begin{tabular}{cccc}
\hline No & Sikap & $\begin{array}{c}\text { Frekuensi } \\
(\mathbf{f})\end{array}$ & $\begin{array}{c}\text { Persenta } \\
\text { se } \\
(\mathbf{\%})\end{array}$ \\
\hline 1 & Unfavorable & 36 & 56,2 \\
\hline 2 & Favorable & 28 & 43,8 \\
\hline & Total & 64 & 100,0 \\
\hline
\end{tabular}

Berdasarkan tabel diatas dapat diketahui bahwa dari 64 responden terdapat sebagian besar responden (56,2\%) bersikap unfavorable terhadap HIV/AIDS di SMAN 3 Seluma Tahun 2017.

\section{PEMBAHASAN}

Berdasarkan hasil penelitian dapat diketahui bahwa sebagian besar responden $(71,9 \%)$ berjenis kelamin perempuan di SMAN 3 Seluma Tahun 2017. Hal ini karena pada saat melakukan penelitian siswi perempuan yang paling berpartisipasi untuk menjawab lembar kuesioner yang peneliti berikan.

Hasil penelitian ini menunjukan bahwa sebagian kecil responden $(3,1 \%)$ berpengetahuan kurang karena dan Sebagian kecil responden $(20,3 \%)$ berpengetahuan cukup tentang HIV/AIDS di SMAN 3 Seluma Tahun 2017.

Berdasarkan hasil penelitian dapat diketahui bahwa sebagian besar dari responden $(56,2 \%)$ bersikap unfavorable dan hampir setengah responden $(43,8 \%)$ bersikap favorable terhadap HIV/AIDS di SMAN 3 Seluma Tahun 2017.

\section{KESIMPULAN}

1. Sebagian besar responden berjenis kelamin perempuan di SMAN 3 Seluma Tahun 2017.

2. Sebagian besar responden berpengetahuan baik tentang HIV/AIDS di SMAN 3 Seluma Tahun 2017.

3. Sebagian besar responden bersikap unfavorable terhadap HIV/AIDS di SMAN 3 Seluma Tahun 2017. 


\section{SARAN}

Berdasarkan hasil penelitian yang telah dilakukan maka peneliti memberi saran kepada:

\section{Teoritis}

Diharapkan dapat menambah wawasan dan menambah ilmu pengetahuan mengenaiHIV/AIDSpadaremaja, sehingga remaja mampu mengetahui hal-hal yang dapat dihindari dalam pencegahan penyakit menular HIV/AIDS.

\section{Praktis}

a. Bagi Institusi Pendidikan SMA 3 Seluma

Diharapkan dapat meningkatkan prilaku atau sikap remaja terhadap pencegahan penyakit HIV/AIDS dan sebagai bahan informasi dan umpan balik dalam rangka pelaksanaan program pemberantasan HIV/AIDS khususnya di kalangan remaja.

b. Bagi Remaja

Sebagai informasi dan menambah pengetahuan remaja tentang bahaya HIV/AIDS, serta dapat mengetahui bahaya dari perilaku berisiko penyakit HIV/AIDS.

c. Bagi Peneliti Selanjutnya

Diharapkan dapat dijadikan refrensi referensi dan masukan untuk penelitian selanjutnya dalam mengembangkan penelitian ini khusunya mengenai HIV/AIDS dengan menggunakan metode dan variabel yang berbeda.

\section{DAFTAR PUSTAKA}

Kemenkes. 2015. Profil Kesehatan Republik Indonesia tahun 2014. Jakarta: Kemenkes RI

WHO. 2015. Global Summary of The AIDS Epidemic. Diunduh dari www.who.int. pada tanggal 18 Maret 2017. 